\title{
QUESTÃO AGRÁRIA NO SÉCULO XXI: OS EFEITOS DO AGRONEGÓCIO PARA AS POLÍTICAS DE REFORMA AGRÁRIA NO BRASIL E EM PORTUGAL
}

\author{
Caetano De Carli (1) $\square$
}

Universidade Federal Rural de Pernambuco | Recife - PE - Brasil 


\section{RESUMO}

Este artigo debate os efeitos da transição do modelo industrial do agronegócio ao modelo financeiro do agronegócio nas políticas públicas de reforma agrária no Brasil e em Portugal. O objetivo é discorrer sobre as disputas de dois projetos desenvolvimentistas presentes no modelo agroindustrial de produção - de um lado, a reforma agrária e, de outro, o agronegócio -, e como esses dois projetos são modificados por essa nova etapa do capitalismo agrário global. Para isso, é utilizada uma abordagem histórica, tendo em vista os casos da questão agrária no sudeste do Pará, em Eldorado dos Carajás, e no sul de Portugal, no distrito de Beja. Para o caso brasileiro, utilizamos do método do caso alargado e entrevistas semiestruturadas; para o caso português, utilizamos de pesquisa documental e história oral. Aponto aqui como efeito dessa inserção do agronegócio nos dois países: a) uma política de contrarreforma agrária; b) controle do mercado de insumos, maquinários, sementes, rações e genética animal por empresas transnacionais; c) aumento no preço dos alimentos; d) estrangulamento da economia camponesa; e) desemprego rural; e f) desertificação rural.

Palavras-chave: agronegócio; reforma agrária; capital financeiro; luta pela terra; campesinato.

\section{AGRARIAN QUESTION IN THE 21ST CENTURY: THE EFFECTS OF AGRIBUSINESS ON LAND REFORM POLICIES IN BRAZIL AND PORTUGAL}

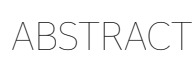

This article discusses the effects of the transition from the industrial model of agribusiness to the financial model of agribusiness and its effects on public policies for agrarian reform in Brazil and Portugal. The objective of this article is to discuss the disputes of two developmental projects present in the agro-industrial model of production, on the one hand agrarian reform, on the other hand agribusiness, and how these two projects are modified by this new stage of global agrarian capitalism. This article intends to use a historical approach, however it is based on a sociological research carried out in Southeast Pará, Eldorado dos Carajás, and a historical research carried out in Southern Portugal, Beja District. For the Brazilian case we used the extended case method and semi-structured interviews, for the Portuguese case we used documentary research and oral history. This article points out as an effect of this insertion of agribusiness in both countries: a) an agrarian counter-reform policy; b) control of the market for inputs, machinery, seeds, feed and animal genetics by transnational companies; c) increase in food prices; d) strangulation of the peasant economy; e) rural unemployment; and f) rural desertification.

Keywords: agribusiness; agrarian reform; financial capital; struggle for land; peasantry.

\section{LA CUESTIÓN AGRARIA EN EL SIGLO XXI: LOS EFECTOS DE LA AGROINDUSTRIA PARA LAS POLÍTICAS DE REFORMA AGRARIA EN BRASIL Y PORTUGAL}

Este artículo discute los efectos de la transición del modelo industrial de agronegocios al modelo financiero de agronegocios y sus efectos sobre las políticas públicas de reforma agraria en Brasil y Portugal. El objetivo de este artículo es discutir las disputas de dos proyectos desarrollistas presentes en el modelo productivo agroindustrial, por un lado la reforma agraria, por otro el agronegocio, y cómo estos dos proyectos son modificados por esta nueva etapa del capitalismo agrario global. Este artículo pretende utilizar un enfoque histórico, considerando los casos de la cuestión agraria en el sureste de Pará, en Eldorado dos Carajás, y en el sur de Portugal, en el distrito de Beja. Para el caso brasileño usamos el método de caso extendido y entrevistas semiestructuradas, para el caso portugués usamos investigación documental e historia oral. Este artículo señala el efecto de esta inserción de la agroindustria en ambos países: a) una política de contrarreforma agraria; b) control del mercado de insumos, maquinaria, semillas, piensos y genética animal por parte de empresas transnacionales; c) aumento de los precios de los alimentos; d) estrangulamiento de la economía campesina; e) desempleo rural; y f) desertificación rural.

Palabras clave: agroindustria; reforma agraria; capital financeiro; lucha por la tierra; campesinado 


\section{INTRODUÇÃO}

O debate sobre a questão agrária no século XXI incorpora um novo modo de produção agropecuária, denominado de agronegócio, em sua escala financeira. Em muitos estudos agrários contemporâneos, seja a sociologia rural, a agronomia, a zootecnia, a veterinária ou a geografia agrária, esse termo é usado para definir toda e qualquer atividade econômica agropecuária que difere da forma tradicional camponesa. Nessa perspectiva, cria-se uma dicotomia entre agricultura familiar x agronegócio, onde tudo aquilo que não é o tradicional, o agroecológico, o orgânico, é classificado como hegemônico. Isso possui, entretanto, alguns efeitos políticos muito preocupantes, como: pautar as políticas agropecuárias a partir de uma lógica urbana; enquadrar a maior parte dos médios produtores rurais, e alguns pequenos produtores, como inimigos; classificar como hegemônica as pequenas e médias empresas rurais; criticar toda e qualquer produção de escala, ainda que seja dentro da lógica do cooperativismo e do campesinato; igualar na mesma escala política uma multinacional e uma pequena empresa rural; não se ater às especificidades de cada produção regional; não se ater às especificidades de cada tipo de produto, entre outros.

Neste artigo, iremos nos concentrar na lógica da economia política na análise da questão agrária, pois se crê que o materialismo histórico-dialético é nossa melhor opção teórico-metodológica para podermos diagnosticar concretamente os territórios do campo historicamente, como também apontar alternativas credíveis e concretas à situação atual. Nesse sentido, o agronegócio significa um modo de produção que, em seu formato atual, se caracteriza pela inserção do capital financeiro e por empresas transnacionais no setor agropecuário em escala global. Mediante tais considerações, iremos elaborar um histórico em relação ao uso, à posse e à propriedade da terra no Brasil e em Portugal, atento aos casos do Pará e do Alentejo, destacando os processos de transição do capitalismo industrial para o agronegócio e como isso interferiu diretamente nas políticas de reforma agrária nos dois países.

Apesar do formato teórico aqui proposto, o que apresentamos, ao longo do texto, refere-se aos resultados de nossa pesquisa a partir dos casos analisados, o caso de Eldorado dos Carajás, Assentamento 17 de Abril, Pará, e o caso da Unidade Coletiva de Produção Terra de Catarina, em Baleizão, Alentejo. Para desenvolver este trabalho, nos valemos do método de caso alargado, entrevistas semiestruturadas e análise em alguns documentos históricos. Em parte da pesquisa sobre o Assentamento 17 de Abril, os recursos 
metodológicos foram voltados a um trabalho de campo in loco utilizando, na medida do possível, o método de caso alargado. De acordo com Santos (1983), esse método consiste em definir critérios de generalizações a partir da especificidade e da riqueza do estudo de caso. Burawoy (1998) também afirma que o método do caso alargado vem a partir de uma proposta reflexiva de ciência que tenta ao máximo fugir da conceituação positivista comumente presente nos manuais de metodologia etnográfica. Em relação à pesquisa em tela, este método foi utilizado de forma parcial. Isso porque seria impossível fazê-lo em Portugal, no contexto da reforma agrária, já que remete a uma pesquisa muito mais histórica do que sociológica. Por se tratar de uma pesquisa comparativa, esse fato também refletiu na estratégia de campo em Eldorado dos Carajás, onde avaliei que a observação-interação proposta por Santos (1983) e Burawoy (1998) não era totalmente suficiente para responder a alguns de meus questionamentos. Mediante a essas considerações, ocorreu-me a ideia de que, para fins de efeito comparativo, a metodologia deveria ser complementada com entrevistas semiestruturadas, a fim de estabelecer uma ligação entre problemáticas similares no caso de Baleizão e de Eldorado dos Carajás. Nesse sentido, a limitação que me foi imposta ao método de caso alargado não me permitiu adotá-lo em sua completitude, mas também tive a preocupação de seguir alguns princípios de tal metodologia. E a melhor solução para isso foi tentar, ao máximo possível, estabelecer uma abordagem metodológica plural.

\section{A TRANSIÇÃO DO CAPITALISMO INDUSTRIAL PARA O CAPITALISMO FINANCEIRO NO SETOR AGROPECUÁRIO}

A sociologia rural nasce a partir da inquietação colocada por Marx (2008), e em determinada forma Engels, no terceiro volume do "Capital" sobre o processo de inserção do capitalismo na agricultura, cuja produção estava organizada de forma précapitalista. Kautsky (1986), no seu clássico livro sobre a questão agrária alemã, irá se debruçar particularmente sobre a questão da renda fundiária que se subdivide basicamente na explicação sobre a renda diferencial I, a renda diferencial II e a renda absoluta, essa última se tratando justamente do empecilho natural que havia da atividade agropecuária em se inserir por completo na sociedade capitalista. Essa questão específica levantava, portanto, qual seria a melhor forma de desenvolver uma sociedade capitalista no campo, debate que envolvia tanto os liberais quanto os socialistas, já que as duas correntes teóricas eram críticas aos sistemas pré-capitalistas de produção, particularmente a servidão e a escravidão. Nos países periféricos e semiperiféricos do sistema 
mundo, esse debate sobre o desenvolvimento dos territórios rurais ganhou, ao longo do século XX, um destaque crucial nos discursos acadêmicos e políticos, devido ao estágio letárgico de pobreza e miséria em que se encontravam os trabalhadores rurais e o campesinato. E, nesse caso, por políticas de desenvolvimento se entendia a elaboração de um amplo programa de reforma agrária.

Nesse contexto, emerge a ideia de reforma agrária como uma solução que traria aos territórios do campo a justiça social, o aumento de produtividade, a distribuição de renda, a formação de uma classe média rural e um mercado interno forte, e que, por fim, impulsionaria o desenvolvimento da indústria nacional. Ainda no século XIX, a França napoleônica e os Estados Unidos pós-guerra de secessão realizaram um processo vigoroso de reforma agrária que foi fundamental para a modernização agrícola e o desenvolvimento da sociedade capitalista nos dois países. No século XX, até determinada altura, a reforma agrária era um consenso entre teóricos socialistas e capitalistas como forma de desenvolvimento dos territórios rurais, bem como de superação de formas sociais arcaicas de produção, embora tivéssemos distintos modelos de operação1. Nos casos brasileiro e português, devido aos compromissos das elites políticas com a classe dos latifundiários, a reforma agrária passou a ser também uma bandeira de luta dos movimentos camponeses organizados. Embora existissem grupos dentro de setores conservadores que também a defendiam, mesmo com ressalvas, o fato é que a reforma agrária foi, geralmente, nos dois países, uma pauta de partidos e movimentos comprometidos com projetos populares e socialistas.

Na década de 1960, nasce, nos Estados Unidos, outro modelo de desenvolvimento do capitalismo no campo que, embora não necessariamente rivalizasse com o modelo de reforma agrária, passa, na prática, a substituí-lo como discurso hegemônico de modernização: o agronegócio ou a revolução verde. Essa revolução viria a solucionar os problemas de improdutividade do meio rural a partir do implemento de maquinários agrícolas, agrotóxicos, fertilizantes químicos, ração controlada, estimulantes hormonais, entre outros. É somente nesse momento que o agronegócio enquanto modelo industrial na produção agropecuária se consolida. Nas áreas rurais de base social pautada no latifúndio, como os casos do Pará e do sul de Portugal, a revolução verde, em sua etapa industrial, ofereceu uma oportunidade

1 Stédile (2020) aponta para as distinções entre o modelo clássico de reforma agrária (Estados Unidos, França, Leste Europeu), modelo de reforma agrária popular (México, Bolívia), modelo socialista (Rússia, Cuba) e as políticas de colonização e assentamento. 
para a transição de latifúndios improdutivos em empresas rurais. Esse processo, entretanto, não foi completo, já que, como já afirmara a teoria marxista da renda absoluta, as dificuldades de inserção do capitalismo em áreas rurais, embora reduzidas pela modernização técnica, ainda era uma realidade.

Sobre o ponto de vista político, no caso português, a região sul de Portugal foi dominada por um histórico sistema do latifúndio, que determinou para ampla maioria da população rural um estágio de pobreza e miséria. No Baixo Alentejo, a organização social desses trabalhadores, mesmo, durante o período da ditadura de Salazar, foi comandada pelo Partido Comunista Português (PCP). Com o fim do fascismo, em 25 de abril de 1974, os territórios rurais do sul do país vivenciaram um período efervescente com inúmeras ocupações de terras por parte dos trabalhadores rurais, capitaneados sob as mais diversas tendências políticas. Emergiram, a partir disso, as brechas institucionais que permitiram a operação da reforma agrária portuguesa e a constituição de milhares de cooperativas e unidades coletivas de produção, gerenciadas pelos próprios trabalhadores rurais. Essas brechas institucionais formataram-se no que Santos (1983) denominou de dualidade de impotências - após o 25 de abril, verificou-se, nos primeiros anos, simultaneamente, uma mobilização social massiva dos trabalhadores rurais alentejanos em prol de ocupação de terras, a emergência de brechas institucionais em nível de Direito e Estado e o subsequente enfraquecimento momentâneo dos instrumentos hegemônicos que regulavam e garantiam a sobrevivência do sistema do latifúndio no Alentejo. Essa movimentação, ao mesmo tempo, não foi forte o suficiente para solidificar as conquistas do 25 de abril para a ruralidade alentejana. Através disso, pouco a pouco, os poderes de regulação foram restaurados e consequentemente a reforma agrária foi derrotada.

No Brasil, nunca se vivenciou um momento tão efervescente politicamente quanto o 25 de abril português. Por outro lado, a luta pela terra demarca formas múltiplas de resistência a três aspectos cruciais da história brasileira, o colonialismo, o latifúndio e o escravismo, como as rebeliões escravas, as lutas indígenas, os movimentos messiânicos, o cangaço etc. Após a fundação do Partido Comunista Brasileiro (PCB), um grupo de intelectuais passou a defender, como alternativa à pobreza e à miséria do meio rural, a reforma agrária. Mediante à metodologia do trabalho de base e da formação política, vários movimentos camponeses organizados nasceram a partir de 1955, sob a influência do PCB. Os mais importantes deles foram as Ligas Camponesas que passaram, de maneira mais enfática, a reivindicar a pauta da 
reforma agrária como principal bandeira de luta. Esse ciclo de luta camponesa e de organização política foi derrotado com o golpe militar de 1964 e a perseguição da ditadura brasileira às principais lideranças desses movimentos.

Apesar desse revés, a causa da reforma agrária não havia sido derrotada e os militares não poderiam deixar que as condições sociais do surgimento desses movimentos camponeses seguissem da mesma forma. Diante disso, ainda em 1964, foi promulgado o Estatuto da Terra, que consolidou no país um esboço de política pública para os pobres do campo, como também uma brecha emancipatória institucional para a realização da reforma agrária. Nas décadas de 1970, os próprios militares utilizaram o estado do Pará para realizar inúmeros assentamentos, dentro do plano de "levar gente sem terra, para terra sem gente" (Stédile 2005). Nessa década, houve início no Brasil de um novo ciclo de luta de classes e organização política no campo, dessa vez organizado por bispos, freiras, padres e freis militantes da Teologia da Libertação. Foi fundada a Comissão Pastoral da Terra (CPT) e dela nasceu posteriormente uma série de movimentos sociais camponeses no novo ciclo de democratização brasileira e, dentro deles, o mais importante, o Movimento dos Trabalhadores Rurais Sem Terra (MST). A luta desses movimentos camponeses gerou, nas décadas de 1980, 1990 e
2000, diversos assentamentos de reforma agrária em todo o país, bem como instituiu uma política pública direcionada especificamente à agricultura camponesa. Essas brechas criadas pela luta política desses movimentos foram insuficientes, porém, para se criar uma real política de reforma agrária no Brasil.

No final do século XXI, esse modelo industrial do setor agropecuário seria alterado por um novo agente: o capital financeiro, representado pelos bancos e pelas empresas transnacionais. Com o processo de contrarreforma agrária portuguesa entre os finais dos anos 70 e 80 , parte das terras devolvidas aos antigos proprietários foram vendidas para empresas multinacionais do ramo do azeite ou outras empresas capitalistas do setor. A elite agrária tradicional alentejana migrou para o setor de vinícolas, de turismo rural, ou para viver de subsídio. A maior parte, entretanto, vendeu a terra e migrou para grandes cidades europeias. No Brasil, em finais da década de 1990, empresas transnacionais passaram a controlar o mercado de terras, de insumos agrícolas, atividade industrial de beneficiamento e mercado varejista de alimentos. Esse é um processo que mais intensificado no início do século XXI, tendo como efeito a inserção voraz do modelo do agronegócio no meio rural brasileiro. Nesse período, o Brasil passa a ser um dos maiores criadores de gado bovino, frango de corte, maior 
produtor de grãos, eucalipto e açúcar do mundo.

Os efeitos sociais desse processo de inserção do capitalismo financeiro no setor agropecuário foram graves. No caso do sul de Portugal, o estágio de letárgico abandono em que se encontra a produção agropecuária, as aldeias e o campo como um todo, evidenciado na falta de empregos, no envelhecimento da população rural e na desertificação populacional, é consequência direta desse novo modelo agrícola. No caso brasileiro, a desigualdade fundiária é a causa fundadora de boa parte dos principais problemas atuais, como o superpovoamento das cidades e a questão do desemprego. Com a inserção do capital financeiro no setor agropecuário, esses problemas só aumentaram e somaram-se a eles a contaminação do solo, dos alimentos, da água (o Brasil consome cerca de $10 \%$ dos agrotóxicos produzidos no mundo) e o crescimento do desmatamento e dos desastres ambientais.

Sobre esse contexto econômico, o processo de luta pela reforma agrária sofre, nos dois países, uma ofensiva conservadora, que se caracterizou por um processo ambivalente onde, de um lado, houve um percurso emancipatório de mobilização social, luta pela terra e espaços institucionais em nível de Estado e Direito para a operacionalização da reforma agrária; e, de outro, houve um percurso regulatório de opressão social e operação política de uma contrarreforma agrária. Em face a esta aparente contradição, a regulação do Estado e do Direito sobrepuseram-se à emancipação social, o que, na reforma agrária, pode ser traduzido na submissão da democratização da terra ao direito de propriedade (De Carli 2014). A necessidade de conhecermos a fundo os meandros políticos e econômicos que permitiram esse destino reside justamente em nossa demanda para pensarmos alternativas credíveis aos territórios do campo. Isso porque a luta das populações camponesas, dos trabalhadores rurais, dos indígenas, dos quilombolas, da população ribeirinha, dos extrativistas, dos pescadores, dos atingidos por barragens e dos atingidos por mineração continua.

\section{USO, POSSE E PROPRIEDADE DE TERRAS NO BRASIL E EM PORTUGAL - OS CASOS DE PARÁ E ALENTEJO}

A questão da terra do Alentejo remonta à formação do reino de Portugal na Guerra de Reconquista contra a ocupação muçulmana da Península Ibérica, época na qual o valor da terra estava relacionado a um território militar e não havia qualquer associação com o mercado. Segundo Coelho (2004:76), "boa parte das terras conquistadas no Alentejo foram entregues a senhorios coletivos: a Ordem de Santiago, a Ordem de Aviz, a Ordem do Hospital, as sés, os 
conventos” e alguns proprietários muçulmanos (que se tornaram cristãos-novos) "mantiveram posse pelo menos duma parte das terras" (Coelho 2004:76). Com a Revolução de Avis (1383), a maioria das terras dos nobres que tomaram partido com a união à Castela foi entregue às ordens religiosas e militares (Coelho 2004). Essa situação perdurou até o século XIX, altura em que a Revolução Liberal nacionalizou os bens da Igreja, mudando parcialmente a posse de terras no Alentejo, mas sem alterar a sua estrutura agrária latifundiária. Para Coelho (2004:79),

[...] as extinções das Ordens Religiosas em 1834 envolveram a expropriação da terra dos conventos a favor do Estado. Mais tarde a Lei da Desamortização de 1861 deu o golpe de misericórdia na terra dos bispados, dos cônegos e das misericórdias. A terra da Igreja foi vendida em hasta pública $e$ comprada pelos capitalistas.

Desde o início do período republicano até ao 25 de abril de 1974, o regime de propriedade sofreu poucas alterações. Entretanto, a terra começava a envolver-se em uma relação monetária, mesmo com a sobrevida do patrimonialismo na mentalidade da maior parte da elite rural. Baptista (2010) refere que algumas atividades agrícolas tradicionais, como a extração de cortiça, a bolota, a criação de porco preto, a vinicultura e a olivicultura, possuíam sua dose de racionalidade econômica, numa associação que envolvia lucros razoáveis ao proprietário, mesmo com produção e empregabilidade baixas nos padrões capitalistas.

A partir de 1929, a ditadura fascista iniciou uma série de políticas públicas com vista à modernização da produção agropecuária, na tentativa de elevar a agricultura alentejana para patamares produtivos mais avançados. As campanhas do trigo, que tiveram como motivações a transformação do Alentejo no "celeiro de Portugal", representaram uma dessas tentativas. Os resultados dessas campanhas, contudo, foram decepcionantes (Fernandes 2006).

Até a década de 1960, a agricultura alentejana, nessa região, era pouco mecanizada, os trabalhadores eram parcamente remunerados (principalmente os temporários) e tinham uma vida bastante precária. "A ausência de alternativas de emprego em nível local e, até os anos 60, a dificuldade de encontrar alternativas fora da região, permitiram assegurar aos donos das terras a disponibilidade de uma reserva de mão de obra barata" (Fernandes 2002:328).

O Alentejo, nessa época, encontrava-se, então, numa pressão demográfica que favorecia a baixa remuneração do trabalho. A situação da fome agravou-se, e datam dessa altura as grandes manifestações camponesas visando o aumento dos salários, a jornada das oito horas e uma maior 
oferta de emprego. Os aparelhos repressivos do Estado Novo foram usados duramente contra os camponeses e em favor dos interesses dos latifundiários. Com isso, a luta pela terra se tornou também a luta contra o regime e fundaram-se, nessa altura, inúmeras células clandestinas do PCP nas aldeias e vilas alentejanas. Além das marchas pela fome, que foram mais recorrentes entre 1946 e 1958, e as greves, como a greve geral no Alentejo e Ribatejo de 1962, outros recursos para sair dessa situação de precariedade laboral foram as migrações para Lisboa e para o estrangeiro (Baptista 1978:12). "A possibilidade de encontrar emprego nas zonas urbanas e, principalmente, o escape aberto pela emigração abriram as portas à debandada dos trabalhadores assalariados, familiares e, mesmo, pequenos agricultores" (Baptista 2010:51).

Na década de 1960, o financiamento de alguns agricultores pelo Estado Novo dinamizou a transformação de vários latifúndios tradicionais em empresas capitalistas. A capitalização ocorria principalmente nas localidades onde os terrenos eram mais férteis (Baptista 1978:48-49). Os terrenos com condições climáticas ou de solos menos vantajosos continuaram a realizar a cultura tradicional do latifúndio. Nas propriedades médias, esse processo de modernização não ocorrera de forma tão acessível, o que culminou num período de crise e de maior dependência do trabalho laboral. A pequena propriedade teve a sua continuidade mesmo com pouco acesso à modernização técnica, mas tomando vantagem pela relativa autossuficiência da mão de obra familiar (Baptista 2010:90). No início dos anos 1970, havia um contínuo avanço da revolução verde no Alentejo, com um aumento considerável do número de tratores, ceifeiras debulhadoras, uso de sementes selecionadas e herbicida (Baptista 2010), beneficiando de significativa ajuda estatal (crédito agrícola, fomento da motomecanização etc.). Com isso, "o 25 de abril encontrou os campos do Sul em grande transformação. Um terço da população que trabalhava na agricultura desertara nos anos 60 " (Baptista 2010:94-95). De certa forma, a reforma agrária freou um processo de desertificação rural que já se desenhava em começo da década de 1970, cujos efeitos mais expressivos foram a migração da população trabalhadora para outros centros, a mecanização da agricultura e o desemprego. Esse quadro, entretanto, é alterado com o 25 de abril de 1974.

Em nível local, o 25 de abril de imediato significou uma possibilidade de retorno à terra natal de muitos emigrados, a liberdade de organização sindical, a cessão dos aparelhos de repressão aos trabalhadores e uma posição de enfrentamento maior dos trabalhadores em 
relação à classe dos latifundiários, historicamente, os maiores beneficiários do fascismo em Baleizão. Foi esse o quadro político que possibilitou, um ano mais tarde, a ocupação dos latifúndios e a formação, nessa aldeia da UCP Terra de Catarina, uma área coletiva de reforma agrária gerida pelos próprios trabalhadores, cujo nome homenageava Catarina Eufémia, militante do PCP assassinada pela Guarda Nacional Republicana (GNR) em 1955, nessa localidade.

O 25 de abril de 1974 instituiu em Portugal o fim do regime fascista e do império colonial, dando espaço para um momento único na história do país. A mudança política veio acompanhada da diversidade partidária, da liberdade política, da emergência de várias organizações sociais e de atores locais nos mais diversos espaços públicos: comitês de bairros, associação de moradores, movimentos sociais, fábricas de autogestão de trabalhadores, grupos de teatro comunitários, o Serviço Ambulatório de Apoio Local (SAAL), imprensa livre, associações estudantis, entre outros. A reforma agrária foi mais um desses processos sociais que emergiram com a Revolução dos Cravos. Para o Alentejo, a reforma agrária foi o estopim de um processo de contestação àquilo que mais representava o poder na realidade local dos campos do Sul na época de Salazar e Marcelo Caetano: o latifúndio.
Após um período de relativa desconfiança em relação ao Movimento das Forças Armadas (MFA), as novas lideranças políticas locais do Alentejo saídas da revolução, constituídas majoritariamente por integrantes e militantes do outrora clandestino do PCP e de outras organizações de esquerda, passaram a celebrar o momento de liberdade política e planejar o modelo de atuação da causa sindical agrícola. Nesse período, a estratégia desses grupos consistiu no fortalecimento da estrutura sindical e na formação de comissões de trabalhadores rurais para negociar com os latifundiários melhores condições de trabalho, mais emprego e aumentos salariais. Essa estratégia, entretanto, funcionou até determinada altura, onde os sindicatos de trabalhadores rurais tinham mais influência. A reação dos agrários, muitos dos quais realmente não possuíam condições financeiras de atender às demandas das comissões, foi, inicialmente, de boicote aos acordos e às comissões. Esse boicote agravou uma tensão já existente entre trabalhadores e patrões. Para fugir dos acordos estabelecidos pelos sindicatos rurais e pelas comissões de trabalhadores, vários proprietários escolheram, enquanto estratégia de enfrentamento, parar a produção ou a descapitalização da propriedade, com a venda de equipamentos, animais e cortiça. Os casos mais famosos desse tipo de descapitalização foram 
a venda intensiva de gado para a fronteira e a destruição de regadios e de instrumentos agrícolas (Baptista 1978).

As primeiras ocupações datam de finais de 1974. Um dos principais agentes dessas ocupações foram os seaeiros e alugadores de máquinas que geralmente haviam investido na compra de máquinas agrícolas, a crédito, para trabalhar por hora para os agrários (Baptista 2010). Com o abandono e o subaproveitamento de alguns dos latifúndios, esses alugadores de máquinas encontravam-se em uma situação de não ter como trabalhar, logo, não ter como pagar o crédito. Com isso, organizaram, junto com trabalhadores assalariados, as ocupações de terras. "Assim ocorreram as primeiras ocupações nos distritos de Évora e de Setúbal, logo nos primeiros meses de 1975" (Barros 1986:61).

Em meados de 1975, o movimento de ocupação de terras ganhou mais intensidade em Évora e Portalegre e "começou a tornar-se claro que se desenham objetivos mais amplos, visando já a real transformação da estrutura da propriedade e da exploração agrícola e a alteração das relações sociais de produção" (Barros 1986:62). Entre agosto e setembro de 1975, o movimento de ocupação de terras atingiu o seu pico em Beja e em Évora, devido à aprovação pelo Governo, em julho, dos decretos-lei 406-A e 407/75, que deram o suporte legal às ocupações. "A partir desse momento, as ocupações deixavam de ser sentidas como ações situadas à margem da lei, antes tendiam a ser vistas pelos ocupantes como atos de execução de leis em vigor" (Barros 1986:63). Tal situação legal acelerou um processo já em andamento. Por um lado, os trabalhadores alentejanos anteciparam-se aos trâmites oficiais, principalmente com a iminência de perderem o período próprio para o cultivo das culturas de verão. Por outro lado, os agrários, com a iminente possibilidade de verem suas terras expropriadas pelo Estado, aceleraram o processo de descapitalização das terras. Além disso, o verão de 1975 foi também "uma época em que importantes sectores do movimento popular consideravam ter chegado o momento de avançar sem demora e o mais longe possível em diversas frentes, com vista a gerar situações de transformação social irreversíveis” (Barros 1986:64).

No mês de setembro, o Governo criou, através do decreto-lei n. 541-B/75, o crédito agrícola de emergência para apoiar os coletivos de trabalhadores da reforma agrária até ao final das colheitas. Podendo ser usado para a remuneração dos trabalhadores, o crédito agrícola de emergência que veio dar um novo impulso aos movimentos de ocupação de terras "até o movimento haver sido bloqueado após a viragem política ocorrida com o 25 de novembro de 1975” (Barros 1986:65). O saldo 
geral das ocupações, segundo Baum (1998:709), foi que "nos finais de 1975 tinham sido ocupados quase 25\% da superfície arável de Portugal (mais de 1,2 milhões de hectares), criando a maior rede de unidades coletivas de produção e cooperativas em sistemas de autogestão da Europa Ocidental".

O processo de ocupações de terras teve diferentes configurações e especificidades dentro do espaço alentejano. Como afirma Baptista (1978:27), "o processo de reforma agrária só avançou e se impôs onde os trabalhadores tiveram capacidade para o levar por diante através do movimento de ocupação de terras". Ou seja, mesmo com a importância de todo apoio de agentes externos à realidade local, como partidos políticos, MFA e técnicos progressistas, a reforma agrária só de fato se materializou onde o movimento camponês teve mais força política e "onde as relações de forças regionais não eram de molde a impedir o processo da reforma agrária” (Baptista 1978:14).

Os distritos nos quais a reforma agrária foi mais efetiva foram Beja, Évora e Portalegre. "Era nesses distritos que os trabalhadores se encontravam mais solidamente organizados” (Baptista 1978:21). Em Beja, o sindicato dos trabalhadores rurais era mais organizado (criado há mais tempo e fortemente associado ao PCP), além de "outras organizações de classe, nomeadamente à Liga dos Pequenos e Médios Agricultores” (Baptista 1978:26). A aposta inicial do PCP foi nas comissões de trabalhadores e investiu nisso, mesmo no momento em que as ocupações fervilhavam em Évora, Portalegre e outras zonas do sul. Entre julho e agosto, e sucessivamente até novembro, as ocupações se generalizaram pelo distrito, constituindo essa região numa das zonas mais intensas da reforma agrária. Foi a "consciência de classe e a organização dos trabalhadores [...] os factores decisivos na alteração das relações de propriedade e de produção nestes distritos" (Baptista 1978:27). "A transferência da posse da terra e dos meios de produção para os produtores directos resultou sobretudo da própria dinâmica do movimento social nos campos do Sul” (Barros 1986:59).

Esse movimento contava, ainda, com a participação ativa das mulheres que possuíam um papel produtivo importante, notadamente na olivicultura e nas culturas de regadio. As mulheres assumiam um protagonismo de combatividade e radicalidade à frente de muitos dos movimentos de ocupações de terras e, segundo Barros (1986:67), "não foram poucos os casos em que, na verdade, a atitude por elas adotada pesou significativamente no avanço para as ocupações e na concretização destas".

O panorama político da reforma agrária foi complexo. Como afirma Baptista (2010:104), "não era só nos campos do Sul que a ordem 
social e institucional, herdada do Estado Novo, se desmoronava. O mesmo movimento atravessava cidades, vilas, bairros, fábricas, escolas, serviços e mesmo quartéis”. Após o 25 de abril, a presidência do general António Spínola foi severamente contestada pelos partidos políticos de esquerda que possuíam muita força política na altura e cujas posições em favor da independência das colônias africanas eram radicalmente contrárias às do general. Convocando a manifestação pública de uma alegada "maioria silenciosa", Spínola se arvorava a estar representando os verdadeiros interesses do povo português, o que advertia os partidos sobre a possibilidade de um novo autoritarismo. Em resposta, o MFA, junto com as organizações sociais de base e os partidos de esquerda, desencadeou um movimento que culmina com a demissão de Spínola. Com isso, reverteu-se um processo de conflito iminente entre, de um lado, os conservadores (com maior peso no norte e centro do país) e os revolucionários (mais centrados em Lisboa e Setúbal e no sul do país). É nessa conjuntura que o general Vasco Gonçalves assumiu o governo e se propõe liderar o processo revolucionário na sociedade portuguesa. Em 11 de março de 1975, setores ligados a Spínola tentaram um fracassado golpe de Estado, que servia de pretexto para Vasco Gonçalves acelerar o apoio oficial ao processo revolucionário, passando o MFA e o próprio Estado, em muitos casos, a ser agentes ativos desse processo. Santos (1984:18) colocou que "o Estado passou a ser uma plataforma múltipla de lutas sociais e políticas e, mais que isso, a questão global da natureza de classe de dominação estatal passou a ser parte integrante da luta política, senão mesmo o objeto privilegiado da luta de classes”.

Com isso que "em 26 de março, o IV Governo Provisório" tomou posse e fez "em 15 de abril o anúncio público da nacionalização dos sectores básicos da atividade econômica (indústria, transportes e comunicações) e de um programa de Reforma Agrária” (Baptista 2010:104). Baptista (2010:105) discute que "as linhas de atuação do IV Governo Provisório (março a agosto) relativamente aos campos do Sul eram três: refazer o aparelho do Estado; apoiar a conquista da terra; definir e aplicar o quadro legal da Reforma Agrária”. Um dos importantes aparelhos criados em nível do Ministério da Agricultura e Pesca foi desvincular as unidades estatais dinamizadoras da reforma agrária do aparelho tradicional de Estado para a agricultura. Tais unidades também tinham como objetivo descentralizar a administração 
do ministério, distanciando-a de uma burocracia muito associada aos interesses dos agrários. Com isso, foram criados oito Centros Regionais de Reforma Agrária, "um no Ribatejo (Santarém) um na Beira Baixa (Castelo Branco), um em Setúbal, um no Algarve (Faro) e três no Alentejo (Beja, Évora e Portalegre)” (Baptista 2010:105). Essas unidades institucionais centralizavam as tarefas do ministério, de modo a ficarem responsáveis por todo o despacho que envolvesse a reforma agrária na região. Baptista (2010:105) argumenta que "houve [...] a preocupação de reforçar os Centros em meios de os dotar com equipas técnicas renovadas que [...] se encontrassem desligados dos interesses dos grandes domínios fundiários”. As tarefas desses centros caracterizavam-se de duas formas: "contrariar ações dos grandes empresários agrícolas e proprietários fundiários para dificultar o arranque da reforma agrária e [...] apoiar as novas unidades de produção" (Baptista 2010:107). Criou-se, portanto, um instrumento institucional renovado tanto em termos dos agentes que o compunham, quanto das antigas estruturas estatais e de funcionários ligados aos agrários e receosos com a reforma agrária. Em relação ao Direito, a reforma agrária exigia um marco legal que regulamentasse as ocupações de terras que já ocorriam mesmo à margem da lei. Esse marco foi consolidado por vários decretosleis². A aprovação da Constituição portuguesa em 2 de abril de 1976 também representou um importante instrumento legal jurídico da reforma agrária. Logo no seu artigo primeiro, referia-se que "Portugal é uma república soberana, baseada na dignidade da pessoa humana e na vontade popular e empenhada na sua transformação numa sociedade sem classes" (Constituição Portuguesa 1976). No artigo segundo, referia-se que "a República Portuguesa é um Estado democrático, baseado na soberania popular [...] que tem por objetivo assegurar a transição para o socialismo" (Constituição Portuguesa 1976). Em seu título I da parte II, no artigo $81^{\circ}$, Incumbências Prioritárias do Estado, descreve que "incube prioritariamente ao Estado: [...] h) realizar a reforma agrária [...]; i) eliminar progressivamente as diferenças sociais entre a cidade e o campo [...]; n) impulsionar

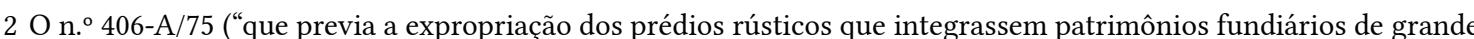
dimensão" e determinava a atuação do Estado na desapropriação dentro de um limite mínimo de hectares por terras), o n. ${ }^{\circ}$ 407-A/75 ("relativo à nacionalização dos prédios rústicos beneficiados por aproveitamento hidroagrícolas situados em zonas de grande propriedade"), o n. ${ }^{\circ} 407-\mathrm{C} / 75$ ("que extinguia as coutadas, exceto as turísticas") e o n. ${ }^{\circ} 406-\mathrm{B} / 75$ ("que definia as normas para o reconhecimento, pela Administração Pública, das unidades de produção da Reforma Agrária”) (Baptista 2010:108). Criou-se ainda, nos casos em que os agrários comprovadamente morassem na terra e provassem que dependiam dela para sobreviver, uma área de reserva à qual eles teriam direito sobre a terra. Essa área de reserva estava diretamente relacionada com o limite mínimo de hectares para desapropriação. 
o desenvolvimento das relações de produção socialistas" (Constituição Portuguesa 1976) .

Até 1976, tanto as estruturas estatais quanto as estruturas no âmbito do Direito de Estado acompanhavam parcialmente a mobilização dos camponeses nas ocupações de terras. Com o cessar das ocupações, os desafios da reforma agrária portuguesa estabeleceram-se sobre a organização da produção e a participação dos trabalhadores nesse processo. Nesse período, entretanto, iniciou-se o processo de ofensiva conservadora política em Portugal, que culminou com a destruição de todo o processo de reforma agrária nos campos do Sul.

A contrarreforma agrária portuguesa foi abrupta e conseguiu, num prazo de aproximadamente cinco anos, restituir todas as terras ocupadas pelas UCP e cooperativas. Hespanha (1986) descreve que a articulação das forças políticas da contrarreforma agrária estabelecia-se em três parâmetros: 1) "no terreno social - promovendo a CAP e fazendo reverter em seu favor o descontentamento de diferentes estratos do campesinato"; 2) "no terreno das ideias - difundindo uma imagem da reforma agrária associada à acção violenta e à ilegalidade"; e 3) "no terreno político - servindose das posições ocupadas no aparelho do Estado para impedir a consolidação das novas unidades de produção e facilitar a reintegração do poder dos proprietários expropriados" (Hespanha 1986:381-382).

Um fator predominante para o fim da reforma agrária portuguesa foi a adesão de parte significativa do Partido Socialista (PS), o grande vitorioso das primeiras eleições legislativas, a um movimento de contenção dos supostos excessos do período revolucionário ${ }^{4}$. Havia uma "preocupação de disciplinar o processo de reforma agrária, contrariando a forma como ele se vinha desenvolvendo 'praticamente sem controlo e nem

3 O Título IV é bem específico à questão da reforma agrária e cita em seu artigo 96: "Objetivos da Reforma Agrária: a reforma agrária é um dos instrumentos fundamentais para a construção da sociedade socialista e tem como objetivos: a) Promover a melhoria da situação econômica, social e cultural dos trabalhadores rurais e dos pequenos e médios agricultores pela transformação das estruturas fundiárias e pela transferência progressiva da posse útil da terra e dos meios de produção diretamente utilizados na sua exploração para aqueles que a trabalham, como primeiro passo para a criação de novas relações de produção na agricultura; b) Aumentar a produção e a produtividade da agricultura, dotando-a das infra-estruturas e dos meios humanos, técnicos e financeiros adequados, tendentes a assegurar o melhor abastecimento do país, bem como o incremento da exportação; c) Criar as condições necessárias para atingir a igualdade efetiva dos que trabalham na agricultura com os demais trabalhadores e evitar que o sector agrícola seja desfavorecido nas relações de troca com os outros sectores" (Constituição Portuguesa 1976).

4 Havia duas intenções políticas claras na tentativa do PS em alterar a reforma agrária: diminuir a influência do PCP, seu mais poderoso adversário político no Alentejo, e estabelecer um modelo próprio de reforma agrária, que, "fora já feito, sobretudo em Beja, com o Movimento Unificado das Cooperativas” (Baptista 2010:131). 
enquadramento por parte dos organismos estatais" (Barros 1986:81) $)^{5}$.

Com a formação do Governo constitucional, Mário Soares, antigo ministro dos Negócios Estrangeiros, assumiu o mandato de primeiroministro, com um discurso moderado, pregando o "fim do gonçalvismo". Lopes Cardoso, em desacordo com as políticas agrárias da maioria de seu partido, renunciou, dando lugar a António Barreto na pasta do Ministério de Agricultura e Pesca. Esse último, em 1977, expediu a lei que pôs fim ao marco legal da reforma agrária, a lei 77/77, também conhecida como "Lei Barreto".

A Lei Barreto fez alterações significativas no sistema de pontuação e de reserva, além de ter atribuído aos antigos proprietários o direito de escolher a parte da reserva que lhes cabia. Nisso, criava-se uma brecha para restaurar a ordem agrária do Estado Novo. Se o direito de propriedade havia sido rompido, a Lei Barreto resgatava-o ao instituir um amplo direito à reserva, que, na prática, estabelecia um duro golpe para o funcionamento das UCP. "Este direito, que só seria atribuído aos que explorassem diretamente a terra e da exploração agrícola retirassem exclusiva ou predominantemente os seus meios de subsistência e da sua família, segundo o Decreto-Lei n. 406A, passa a poder ser requerido por qualquer proprietário" (Barros 1986:81).

Baptista (2010:164) avalia que "de uma legislação que visava uma ampla Reforma Agrária passa-se, com a Lei 77/77, a uma tentativa de, principalmente, refazer e consolidar o domínio do capitalismo agrário”. Hespanha (1986) destaca, ainda, que, em níveis de Estado, houve uma mudança significativa nos Centros de Reforma Agrária, com o afastamento dos técnicos progressistas e sua substituição pelos mais simpáticos aos latifundiários. Assim, os Centros de Reforma Agrária, que antes trabalhavam em prol da legalização das terras ocupadas, transformaramse em "meros serviços de "entregas de reservas"” (Hespanha 1986:388).

Na década de 1980, mais de $80 \%$ das áreas da reforma agrária foram entregues aos antigos proprietários, a partir do "direito de reserva”. Gallo (2002) narra a forma como geralmente ocorria a desapropriação: "Os cooperantes decidem

5 Com esse intuito, foi formada uma “'Comissão de Análise e Estudo dos Problemas Surgidos com a Aplicação da Reforma Agrária', nomeada pelo Ministro da Agricultura e que tinha como objetivo averiguar os casos de ilegalidade na Reforma Agrária” (Baptista 2010:130). "Com base nos seus trabalhos que o VI Governo Provisório devolveu 889 hectares indevidamente ocupados. Foi também este Governo que entregou as primeiras 28 reservas, com um total de 1480 hectares, e que retirou 177 ha às unidades de produção da Reforma Agrária para entregar aos seareiros [...]. Foram intervenções de pouca amplitude, mas que, acompanhadas por iniciativas que tentaram forçar a presença do PS na Reforma Agrária, apareciam à maioria dos trabalhadores como um sinal de possível destruição das suas unidades de produção. Por outro lado, para a CAP e para o sector dominante do PS, eram resultados manifestadamente insuficientes" (Baptista 2010:130). 
protestar, no dia da entrega, na herdade a tirar, e recusam-se a sair. Com a intervenção da GNR, avisada pelos agrários, a herdade é entregue, uns cooperantes agredidos, outros presos" (Gallo 2002:177). Desta forma, uma a uma, a maioria das terras das UCP foi retirada do controle dos trabalhadores e a ordem latifundiária restabelecida nos campos do Sul.

Algumas UCP e cooperativas conseguiram uma sobrevida na década de 1980, mas à custa de muitas dificuldades, sem nenhum apoio institucional do Estado, com várias dívidas (principalmente com o Crédito Agrícola de Emergência) e com uma acentuada redução das terras, da sua produção e, consequentemente, de seus trabalhadores. No campo jurídico, a revisão constitucional de 1982 deu início a uma série de alterações em vias de reduzir os compromissos ideológicos originalmente assinados em 1976, especialmente a parte que se referia à "transição ao socialismo". A revisão constitucional de 1989 eliminou qualquer referência à reforma agrária, deixando "às maiorias parlamentares a competência sobre a oportunidade e modos de efetuar eventuais modificações nas estruturas fundiárias" (Masseno 1996:7). Segundo Masseno (1996:7), tal alteração também adequou as normas da agricultura portuguesa "à aplicação da Política Agrícola Comum”, no processo de adesão de Portugal à comunidade europeia em 1985.
O período final da reforma agrária coincidiu com esse processo de entrada de Portugal na Comunidade Econômica Europeia (CEE). Na década de 1990, as reformas da Política Agrícola Comum estabeleceram alguns subsídios sobre a terra improdutiva, o que, segundo Baptista, contribuiu para que parte dos latifúndios alentejanos passasse a ser gerido "com o objetivo de maximizar uma renda fundiária sem qualquer finalidade produtiva" (Baptista 2010:14). Vários dos antigos proprietários venderam suas terras a grupos estrangeiros que "têm implantado explorações muito intensivas, com pesadas consequências ambientais e, com frequência, recorrendo à mão de obra imigrante sazonal" (Baptista 2010:14).

Em relação aos trabalhadores, logo após o processo de entrega das reservas, muitos se decidiram pela migração para o estrangeiro ou para as cidades, principalmente Lisboa. As oportunidades de trabalharem na região ficaram cada vez mais reduzidas. Muitos dos que permaneceram foram os beneficiados com a aposentadoria. Com isso que "no Alentejo, para os trabalhadores agrícolas a terra deixou de ser um polo de conflitualidade e os imigrantes [...] não têm condições para qualquer reivindicação sobre a terra" (Baptista 2010:15).

No caso do brasileiro, a ocupação territorial da Amazônia pelos colonizadores data da formação das 
primeiras missões jesuítas ao longo das margens e afluentes dos principais rios da região. A produção das missões girava em torno de canela, cravo, tabaco, cacau e castanha. Em 1750, é fundada pelo Marquês de Pombal a Companhia de Comércio do Grão-Pará e Maranhão, que "tinha o total controle da comercialização de bens e fatores produtivos, detinha o monopólio do comércio de escravos, oriundos da África, e a exclusividade na venda de todas as mercadorias produzidas na Amazônia” (Vergolino \& Gomes 2004:448). No século XVIII, o sul paraense começou a ser colonizado pelas atividades de mineração nos rios Araguaia e Tocantins. "Com o esgotamento dos minérios, as populações ribeirinhas passaram a viver da caça, da pesca e do extrativismo vegetal" (Ferraz 1998:40). No século XIX, pequenos criadores de gado começaram a se deslocar do Maranhão para o Pará.

Nas primeiras décadas da República, essa região passou por um período abrupto de crescimento econômico graças ao ciclo da borracha, que foi o principal responsável pelo relativo progresso urbanístico, principalmente em Belém e Manaus. Após esse ciclo, a economia paraense se direcionou para exportação de madeira e castanha. Nos anos 1940 e 1950, a construção de obras de infraestrutura, como a rodovia Belém-Brasília e Brasília-Acre, impulsionou o desenvolvimento e instituiu uma nova forma de ocupação do solo (Vergolino \& Gomes 2004). Ferraz (1998:48) explica que "com a crise da borracha, os seringueiros e alguns seringalistas se tornaram sitiantes, fazendeiros ou latifundiários. Espalharam-se pelo território à deriva do meio e da amplidão territorial”. Essa ocupação, geralmente, não era acompanhada de regulação legal da propriedade, o que, inicialmente, para a época, não gerou muitos conflitos intraproprietários, já que a terra, para tal estrato social, era abundante. Para os indígenas, entretanto, foi um período de contínuas diásporas, quando não de matanças indiscriminadas de tribos (Ferraz 1998).

No aspecto demográfico, a construção da estrada Belém-Brasília intensificou o fluxo de migrantes vindos da região Centro-Oeste e Nordeste do Brasil. "A vida era difícil para os chegantes. Eram todos pobres. O povo bebia água de cipó e comia só carne de caça. [...] Enfrentaram a malária, que fez muitas vítimas. Morria tanta gente que nem se fazia mais visita por luto" (Asselin 1982: 26). As terras foram gradativamente tomadas pelos trabalhadores das rodovias e alguns empreiteiros vindos do Sul do país formaram grupos de homens para ocupá-las, na medida em que as estradas iam sendo construídas. Constituíram-se, assim, novas categorias de latifúndios e posseiros: "chegaram, sucessivamente, lavradores mineiros, baianos e 
capixabas, que formaram um tipo de classe média rural, uma vez que traziam um certo capital, empregavam mão de obra para efetuar a derrubada, e ocupava, cada um, 200, 300 e até 500 hectares" (Asselin 1982:25). O processo de territorialização da propriedade privada não foi de forma alguma pacífico, datando uma grande violência de expulsão dos antigos moradores da região, dos indígenas e dos antigos posseiros. "Foram também anos de 'caça aos índios' na beira do Rio Tocantins. Pelos anos 64-65, houve a chacina dos índios Gaviões" (Asselin 1982:27). Após o golpe militar, qualquer resistência dos posseiros e dos índios passou a ser incluída na categoria de crimes políticos.

No período militar (1964-1985), o projeto de modernização foi consolidado na Amazônia. Um dos símbolos desse processo foi a construção de inúmeras rodovias federais e estaduais, com destaque para a BR-232, a rodovia Transamazônica que gerou um novo fluxo migratório a esse território. Com a chegada de um grande número de trabalhadores e de novos ocupantes, os conflitos de terras se avivaram ainda mais, com destaque para o confronto entre posseiros e grileiros (Ferraz 1998).

Na década de 1970, a ditadura militar promoveu um plano de ocupação do território na Amazônia que incluiu a reforma agrária como política de colonização. Formaram-se inúmeros assentamentos de reforma agrária no meio da floresta, onde o agricultor ganhava um lote e todo o tipo de dificuldade, entre as quais as maiores eram: falta completa de infraestrutura, necessidade de desmatar a área para plantar e epidemia de malária. Concomitante a isso, foram criados, mesmo ilegalmente, diversos sindicatos, auxiliados pelo trabalho da ala progressista da Igreja Católica, completamente à revelia da ditadura militar. Os sindicatos tentavam atuar em defesa principalmente dos trabalhadores rurais e dos posseiros.

O Estado, enquanto agente mediador do conflito, tendia quase sempre para o lado mais forte, as empresas e os proprietários de terras. No processo de oficialização do direito de propriedade na Amazônia, "a mudança de conceito e o formalismo jurídico serão usados como instrumento de expansão do domínio fundiário dos grupos mais fortes” (Ferraz 1998:52).

É no meio dessa conjuntura conflituosa entre grileiros e posseiros que, entre 1972 a 1974, foi instaurada na região do Bico do Papagaio, por um grupo de aproximadamente 100 pessoas ligadas ao Partido Comunista do Brasil (PCdoB), a Guerrilha do Araguaia, o maior foco de resistência armada à ditadura militar. "O esboço da ação guerrilheira entre o Tocantins e o Araguaia [...] influenciou decisivamente a política do Estado para as áreas de conflito na Amazônia” (Ferraz 1998:62). Os 
militares, temerosos com a possibilidade de implodir uma forte reação armada camponesa na região, deslocaram para a área um alto número de soldados e equipamentos, desencadeando uma repressão intensa, não somente em relação aos militantes, mas aos camponeses, indígenas e a qualquer um que estivesse na linha de frente do conflito. A Guerrilha do Araguaia durou dois anos, mas as suas consequências continuaram nos anos subsequentes. Nesse período, o Exército e seus demais aparelhos de repressão atuavam contra os guerrilheiros e os camponeses, muitas vezes destruindo casas, vilas, incendiando lavouras, executando sumariamente prisioneiros, deixando um lastro de horror e repressão na região. Essa "limpeza da área" foi sequenciada por uma política que executou um investimento agressivo de incentivos às empresas rurais que proliferaram sobre os rastros da ação militar. Alojavam-se, portanto, novos proprietários vindos de fora, algumas empresas se tornaram proprietárias, tudo com o intuito de "pacificar" a área.

Apesar do fim da guerrilha, qualquer oposição e organização ao sistema de grilagem, ou aos grandes projetos da área, fosse feita por organizações sindicais clandestinas ou por grupos de camponeses ou trabalhadores rurais, era arduamente reprimida com a justificativa ainda de ser um resquício da Guerrilha do Araguaia.
Na década de 1970, iniciou-se um período de compra de terras por empresas de grande porte, notadamente a Companhia Vale do Rio Doce, que expandia as suas atividades mineradoras na Serra dos Carajás. Alguns bancos, como o Bamerindus e o Bradesco, e empresas sem ligação com o setor agropecuário, como a Volkswagen, tinham, respectivamente, 54.597 ha, 61.036 ha e 139.392 ha espalhados no sul paraense (Emmi 1999:110) Segundo Andrade (1981), o controle de uma ampla reserva de terra por grandes empresas na região amazônica criou uma situação particular, na qual havia maior facilidade em conseguir autorização do Estado para exploração dos minérios do solo. Assim, estabelece-se a formação de "verdadeiras 'capitanias', em que uma empresa transnacional, comprando terras baratas e obtendo subsídios governamentais e isenções de impostos, implanta um verdadeiro Estado dentro do Estado" (Andrade 1981:47). Além disso, muitas empresas compravam terras unicamente como reserva de mercado, o que se explica pela economia inflacionada, onde a terra se tornava garantia do patrimônio do banco, para o caso de uma perda colossal do valor do papel moeda (Andrade 1981).

No final dessa década, o governo militar, com a pretensão de eliminar o conflito de terras a partir da expulsão dos posseiros da região, retirou os poderes do Instituto Nacional de Colonização 
e Reforma Agrária (INCRA) e criou o Grupo

Executivo das Terras do Araguaia-Tocantins (GETAT). Com isso, o INCRA perdia seu poder de atuação na área, para entrar diretamente um órgão que era vinculado ao Conselho de Segurança Nacional (Ferraz 1998:91). A principal intenção do GETAT era pacificar a região e, dentro desse intuito, consolidou-se, mesmo em regime ditatorial, uma brecha para a atuação da CPT e de advogados populares que passavam a atuar em defesa do elo mais fraco do conflito, os posseiros. Poucos meses depois da criação desse órgão, e quando as articulações entre Estado e Igreja tendiam a dar algum alento aos posseiros, descobriu-se ouro na região de Serra Pelada, criando uma enorme área de garimpo a céu aberto na região. "Em poucas semanas, Serra Pelada e outras dezenas de garimpos estavam coalhados de antigos posseiros, sem-terras e outros trabalhadores desempregados e subempregados, que largaram tudo para tentar a sorte grande" (Ferraz 1998:97). O processo de busca desenfreada pelo ouro só veio a intensificar a violência da região, onde se criou uma grande fileira de miseráveis.
Na década de 1980, o conflito entre grileiros e posseiros chegou ao seu pico. O GETAT executava a reforma agrária "visando realizar regularizações fundiárias, titulações de forma a adequar os considerados casos críticos aos dispositivos jurídicos existentes, mantendo inalterável o regime de posse, uso e propriedade existente" (Medeiros 2003:33). Iniciava-se, assim, um programa de reforma agrária em área de conflito, onde basicamente dava-se terra ao vencedor do confronto armado. Então, se o posseiro sobrevivesse, o Estado legalizava a sua posse. Caso não, se oficializava a terra em favor dos grileiros. Muitos dos posseiros, entretanto, não estavam dispostos a entrar nesse tipo de disputa e passaram, cada vez mais, a procurar os sindicatos rurais. No final da década de 1980, a atividade sindical passou a ser muito considerável, como também o foram as lideranças assassinadas nesse período, como o sindicalista João Canuto ou o deputado petista João Batista ${ }^{6}$. É nesse contexto que surge o MST, nessa região, como algo novo, um movimento camponês organizado nacionalmente.

Em 17 de abril de 1996, data do Massacre de

6 Emmi mostra que, somente no ano de 1985, em janeiro, em Xinguara e Marabá, no Castanhal Pau Ferrado, morreram dez pessoas; em maio e junho, em Marabá, no Castanhal Surubim, morreram oito pessoas; em junho, em São João do Araguaia, no Castanhal Ubá, morreram nove pessoas; em Marabá, no Castanhal Fortaleza, morreram 12 pessoas; e, em setembro, também em Marabá, no Castanhal Princesa, morreram cinco pessoas. (Tabela 12, Emmi 1999:134). Essa violência não somente representa um mal banalizado (Arendt 1999), mas suas razões advêm das fragilidades legais que envolvem a posse de terra no estado do Pará. Ou seja, a violência é um elemento-chave na composição política que garante a ordem social na estrutura fundiária em níveis locais. A violência não é algo inerente a qualquer racionalidade econômica e política. A violência é, sim, parte do negócio de terras no estado do Pará (De Carli 2014). 
Eldorado dos Carajás, já se passava oito anos da promulgação da Constituição, já se realizara duas eleições livres para presidentes e muitas outras para governador, prefeito, deputados e senadores, já havia se restituído o livre direito de organização sindical e partidária, mas, ainda assim, na vida prática dos camponeses entrevistados em Eldorado, a cidadania era algo que não existia. Com o Massacre de Eldorado dos Carajás e as denúncias que se formaram acerca dessa tragédia, a cidadania foi trazida aos sobreviventes como compensação ao banho de sangue. Assim que foi construído não somente o Assentamento 17 de Abril, como também toda a política para a reforma agrária na nova República brasileira. A partir daquele momento, iniciou-se também uma territorialização do MST no Pará. Antes circunscrito à região do Bico do Papagaio, o MST passou a atuar também na região de Belém, a fim de procurar avançar a sua relação política com os meios urbanos e com o núcleo do poder institucional na capital. Ao fim, foram assentadas 690 famílias. O poder político do latifúndio e a hegemonia da propriedade privada, tanto em termos de Direito quanto do Estado, sofreram uma derrota. Entretanto, o custo da desapropriação foi muito caro. Como falou Luciano Luciano (comunicação pessoal, Eldorado dos Carajás, 9 de abril de 2012):
Saiu cara essa terra para nós. Quando se diz cara, porque sangue é vida, são coisas que não têm preço. E ela foi feita, essa reforma, desapropriação aqui, mas em troca de sangue. Então, essa terra aqui não tem preço que pague, porque ela saiu muito cara, porque o sangue, a vida, é a coisa mais importante.

O Assentamento 17 de Abril é uma das maiores áreas da reforma agrária sob a coordenação do MST no Brasil. Quando o Complexo Macaxeira foi desapropriado, os trabalhadores permaneceram na sede da fazenda e iniciaram um plantio de subsistência para garantir o alimento de todos. Conquistara-se a terra, mas o INCRA não havia repartido a área, nem fornecido qualquer tipo de auxílio. Um ano depois, foi liberado pelo INCRA um fomento de 400 reais e um crédito de 2.000 reais por família para a construção das casas. Os locais da residência foram sorteados. Os assentados organizavam-se em 17 grupos. O INCRA marcou, para cada grupo, um dia para realizar o sorteio. Em seguida, sortearam os lotes. Alguns ficaram mais próximos da vila, outros mais afastados. Uns localizavam-se em área de mata nativa. Outros, a maioria, em área de pasto, que correspondia a cerca de $80 \%$ da área do complexo Macaxeira. Uns lotes cortavam um riacho, outros ficaram mais próximos da estrada que faz fronteira entre o assentamento e a cidade de Eldorado dos Carajás.

Flávio conta que, no começo, a união de 
todos fazia o assentamento parecer uma única família: "É um povo que se dá bem demais. São os barraquinhos de lona aí. Os caras com a rede armada, e aquela festa, festa mesmo. É uma união tremenda. Então é muito bom que até hoje eu digo isso, tenho até saudade" (comunicação pessoal, Eldorado dos Carajás, 8 de abril de 2012). Nessa época, essa união entre os assentados refletiu-se na produção. Organizaram-se roças coletivas que chegaram a produzir, no ano de 1998, 30.000 sacas de arroz, além de mandioca e milho, tirando o suficiente para sustentar o assentamento e também para que fosse comercializado o excedente para Eldorado dos Carajás.

Criado e consolidado o Assentamento 17 de Abril, começou-se a conviver com alguns dilemas e problemas. Aos poucos, entretanto, a vida do assentamento ia-se estruturando. Inicialmente, não havia luz, nem água, nem estradas. A escola era improvisada no meio da área central da vila, construída pelos próprios assentados com tábuas de madeira. O posto de saúde também era precarizado, faltava serviço médico e de enfermaria. A política de reforma agrária se restringiu a ceder à terra as famílias assentadas. A experiência do Assentamento 17 de Abril simbolizou, na prática, a residual e ineficiente política de reforma agrária do governo Fernando Henrique Cardoso (1995-2002).

Sob o ponto de vista da economia política, além das pressões sociais dos movimentos camponeses, alguns outros fatores contribuíram para o programa de reforma agrária do governo FHC. Pereira (2013) aponta que os efeitos do Plano Real e da "dolarização" da economia prejudicariam o latifúndio agroexportador de duas formas: 1) com o real com cotação similar ao dólar, o ganho real do latifúndio nesse setor caiu; 2) os preços das terras no Brasil sofreram uma forte baixa na transição de uma economia inflacionada para uma estabilidade financeira, que, entre outras medidas, foi conseguida através de um fortalecimento de uma supervalorização do real.

Na eleição de 2002, criticando duramente o programa de reforma agrária de FHC, Lula lançou o Programa Vida Digna no Campo, que continha uma ideia de que era perfeitamente possível a conciliação entre um projeto de reforma agrária e um programa para o fortalecimento do agronegócio. Em 2003, vários movimentos camponeses, incluindo o MST, lançaram o Programa Unitário dos Movimentos Camponeses e Entidade de Apoio, no qual se estabeleceu "a realização de uma ampla reforma agrária e o fortalecimento da agricultura familiar, pois só elas garantirão o direito ao trabalho para a população rural, historicamente excluída, e a produção de alimentos para o mercado interno" (Programa Unitário dos Movimentos Camponeses e Entidade de Apoio apud Stédile 
2005:233). No programa, incluía-se a necessidade de desapropriação dos latifúndios improdutivos, de aprovação de uma lei de limite máximo da propriedade de terras, o confisco de terras com trabalho escravo ou infantil, o reconhecimento dos territórios dos povos tradicionais e a implementação de políticas de educação, saúde, cultura, crédito e de agroindústrias, bem como a produção de sementes pelos próprios agricultores. Mesmo com grandes diferenças entre o programa do governo e o programa dos movimentos sociais, houve expectativa de que o governo Lula realizasse um programa de reforma agrária mais amplo.

No governo Lula, em um primeiro momento, os aparelhos institucionais para a desapropriação de terras foram significativos. Entretanto, o seu governo se destacou por uma série de políticas que se voltaram à estruturação dos assentamentos, como o Programa Luz para Todos, o Bolsa Família, a aposentadoria rural e o Programa das Cisternas no Semi-Árido. O poder de regulação do Estado que inibia as ocupações de terras, no entanto, foi mantido, notadamente o despacho ministerial que proibia vistoria do INCRA sobre terra ocupada durante o período de dois anos. Paralelo a isso, um novo programa do governo, apesar de extremamente necessário, de certa forma, atenuou a demanda social em prol da luta pela terra: o bolsa família. Em termos de violência no campo, conseguiu-se diminuir notadamente os casos dos agentes do Estado, apesar de continuar a verificar-se vários assassinatos de lideranças rurais por grupos paramilitares. Após 2008, o governo Lula recuou drasticamente o número de desapropriações de terras.

O governo Dilma Rousseff (2011-2016) seguiu a atuação política dos últimos anos do governo Lula, onde os números de desapropriações de terras, para reforma agrária, reduziram-se para quase zero. Apesar disso, foi estabelecido um programa de habitação rural que melhorou sensivelmente as condições de vida dos assentados, dos quilombolas, dos pequenos agricultores e da população indígena. Os dois governos, entretanto, priorizaram efetivamente a inserção do capital no setor agropecuário, na mineração e no setor energético, independente dos custos sociais e ambientais na época. Nos governos Temer (2016-2018) e Bolsonaro (2019-atual), qualquer possibilidade remota de retomada das políticas de reforma agrária foram perdidas e, consequentemente, chegou-se ao fim da política de reforma agrária em área de conflito.

Essa perda da operacionalidade política da reforma agrária teve como pano de fundo uma materialidade econômica. Delgado (2013) afirma que houve, no período do governo Lula, uma restruturação das cadeias produtivas no 
setor agropecuário, um maior oferecimento do crédito agrícola, principalmente para grandes investimentos no setor, e ainda um maior aquecimento no mercado de terras, notadamente com a entrada de empresas transnacionais no ramo agropecuário. Durante o governo Dilma, ocorreu um processo de "reprimarização do comércio exterior", onde o crescimento do produto interno bruto (PIB), nos períodos iniciais do governo Lula, foi alavancado pelo setor primário. Delgado (2013:66) afirma que esse sucesso aparente pode ser quantificado em "uma quadruplicação do seu valor em dólares - o valor médio anual das exportações de 50 bilhões de dólares no período 1995-1999 cresce para cerca de 200 bilhões no final da década de 2000”.

Esse processo foi acompanhado por uma série de mecanismos de inserção do capital na agricultura, como: 1) a compra de ações de empresas que atuavam no setor agropecuário por bancos; 2) a dolarização da economia mundial, que favoreceu a entrada de empresas transnacionais no mercado de terras locais; 3) as teses do livrecomércio propagadas pelo Banco Mundial e pelo Fundo Monetário Internacional e "os acordos multilaterais, que normatizaram o comércio de produtos agrícolas de acordo com os interesses das grandes empresas e obrigaram os governos servis a liberalizarem o comércio desses produtos"; 4) uma maior dependência da agricultura em relação ao crédito bancário; 5) o abandono de "políticas públicas de proteção do mercado agrícola nacional e da economia camponesa"; 6) a compra de terras do Sul global como reserva de capital de empresas transnacionais do Norte; 7) o investimento no setor de biocombustíveis; 8) a internacionalização dos preços médios dos produtos agrícolas; 9) a privatização da pesquisa e da tecnologia no setor agropecuário, vide o caso da biotecnologia; 10) o aumento da produtividade agrícola "combinada com o aumento de escala dos monocultivos e com o uso intensivo de venenos e máquinas agrícolas"; 11) a "redução da classe de trabalhadores proletários rurais"; e 12) aumento da utilização de químicos e produtos farmacêuticos na produção agropecuária (Stédile 2013:21-31).

Assim, se, anteriormente, a reforma agrária era um projeto de superação da pobreza e de um sistema improdutivo do latifúndio, que envolvia uma articulação de interesses combinados entre diversos setores, como movimentos campesinos, agentes estatais e, até mesmo, setores da elite econômica e política, atualmente, a reforma agrária passou a ir de encontro a todas essas mudanças efetuadas no setor agropecuário. Num período pautado pelas políticas neoliberais, em que o Estado, cada vez mais, acompanha os interesses do mercado, em detrimento de suas funções 
constitucionais de regulação social e econômica, a reforma agrária se retraiu enquanto política pública. Com isso, apesar de os movimentos camponeses continuarem a ser o elo mais forte da esquerda orgânica em termos de mobilização social contra o golpe de 2016 e a favor da liberdade de Lula, operou-se, no Brasil, um silencioso processo de contrarreforma agrária, que teve como pano de fundo econômico a inserção do capital financeiro no setor agropecuário. Em contraponto a esse modelo agrícola do agronegócio, o MST, a partir da realização do seu VI Congresso Nacional em 2016, vem construindo um novo contraponto, chamado de projeto de Reforma Agrária Popular.

\section{CONCLUSÃO}

A comparação do caso brasileiro com o caso português nos traz um ponto de vista genérico a respeito dos conflitos referentes ao processo de transição do capitalismo industrial no setor agropecuário nos dois países, onde dois projetos muito claros estavam em disputa: de um lado, o projeto hegemônico da etapa industrial da revolução verde, que reunia os interesses dos latifundiários e das empresas rurais; de outro, o projeto da reforma agrária, pauta histórica dos movimentos camponeses organizados. A comparação histórica nos traz vários meandros e complexidade a esse esquema, pois, a rigor, existiu, portanto, tanto projetos de reforma agrária conservadores (e os projetos de colonização na Amazônia foram um claro sinal disso), como formas de inserção da economia camponesa na lógica industrial de produção. Apesar disso, observase uma tendência na qual, majoritariamente, os processos de reforma agrária adquiriram um caráter popular e a revolução verde, em sua etapa industrial, uma natureza hegemônica.

Uma nova e complexa engrenagem, entretanto, se materializa no cenário da produção agropecuária em escala global: o capital financeiro e a globalização neoliberal. O conflito entre latifundiários e camponeses, decorrente do processo de inserção do capital industrial no setor agropecuário, foi gradativamente transformandose num confronto de maiores proporções, com a constituição de uma nova economia capitalista no meio rural, pautada na participação direta de bancos, empresas transnacionais, empreiteiras e mineradoras. Assim, esse conflito foi remodelado a partir da criação de uma nova forma de elite, muito mais poderosa do que o antigo latifúndio, uma invisível e anônima burguesia agrária global, ou seja, nas corporações transnacionais que compõem o setor do agronegócio.

No Brasil, a luta pela terra passa por uma situação muito difícil, com a diminuição do número de camponeses, a restrição das políticas públicas às 
políticas assistencialistas, o avanço do capital sobre outras fronteiras agrícolas, o recuo político-ambiental do código florestal, a construção de grandes obras desenvolvimentistas para o meio rural e, por fim, com a ascensão de um governo de extrema-direita que teve entre os programas de campanha considerar o MST um movimento terrorista. Para Portugal, o declínio da vida social do meio rural é o maior sintoma de como foram pensadas as políticas na agricultura portuguesa ao longo de 30 anos. Assim, não somente a luta pela terra arrefeceu em tal localidade, mas a própria vida social. Isso pode ser notado no envelhecimento das aldeias, no declínio da economia local, no declínio da agricultura camponesa e da soberania alimentar nacional.

Ao fim, nos dois casos, os interesses do agronegócio foram se sobrepondo aos direitos democráticos, aos direitos humanos, ao direito do meio ambiente e, consequentemente, à própria política de reforma agrária. O meio rural, que dantes era considerado um eixo periférico no capitalismo, torna-se, cada vez mais, um de seus eixos centrais. Os mercados de commodities, água, mineração e energia estão hoje no eixo do capitalismo global. Assim, é a reforma agrária não mais um meio para atingir um fim, mas é ela própria uma das finalidades das lutas anticapitalistas. Em termos gerais, sob o contexto brasileiro e português, pode-se colocar que cada vitória da reforma agrária foi uma derrota para o capitalismo e, consequentemente, cada derrota da reforma agrária foi uma vitória para o capitalismo.

\section{REFERÊNCIAS}

Andrade, M. C. 1981. Nordeste: a reforma agrária ainda é necessária? Recife: Guararapes.

Arendt, H. 1999. Eichmann em ferusalém. Um Relato sobre a Banalidade do Mal. São Paulo: Companhia das Letras.

Asselin, V. 1982. Grilagem: corrupção e violência em terras de Carajás. Petrópolis: Editora Vozes.

Baptista, F. O. 1978. Portugal 1975: os campos. Lisboa: Afrontamentos.

Baum, M. 1998. Autogestão e cultura política: o impacto da reforma agrária no Alentejo vinte anos depois. Análise Social 33(148):709-740.

Baptista, F. O. 2010. Alentejo: a questão da terra. Loulé: 100Luz. 
Barros, A. 1986. Do latifundismo à Reforma Agrária. O caso de uma freguesia do Baixo Alentejo. Oeiras: Fundação Calouste Gulbenkian.

Burawoy, M. 1998. The extend case method. Sociological Theory 16(1):4-33. DOI: https://doi. org/10.1111/0735-2751.00040

Coelho, A. B. 2004. Lugar da Reforma Agrária na história das questões fundiárias no Sul de Portugal, in Uma revolução na revolução. Reforma Agrária no Sul de Portugal. Organizado por A. Murteira. Montemor-o-Novo: Campo dasLetras.

Constituição Portuguesa. 1976. Princípios Fundamentais. Assembléia Constituinte. Debates Parlamentares. Catálogos Gerais. Direção de Serviços de Documentação e Informação. Disponível em: http://debates. parlamento.pt/r3/dac/constituicao/c_76-2.aspx. Acesso em: 4 de abril de 2013.

De Carli, C. 2014. Sonhos de abril. A luta pela terra e a reforma agrária no Brasil e em Portugal, os casos de Eldorado dos Carajás e Baleizão. Tese de Doutorado, Universidade de Coimbra, Coimbra.

Delgado, G. 2013. Reestruturação da economia do Agronegócio - Anos 2000, in A questão agrária no Brasil volume 7: O debate na década de 2000. Organizado por J. P. Stédile, pp. 57-88. São Paulo: Expressão Popular.

Emmi, M. F. 1999. A oligarquia do Tocantins e o domínio dos castanhais. Belém: UFPA/NAEA.

Fernandes, M. 2002. A organização dos trabalhadores agrícolas na reforma agrária: o caso de Baleizão. Ethnográfica 6(2):327-345.

Fernandes, M. 2006. Terra de Catarina. Do latifúndio à reforma agrária, ocupações de terras e relações sociais em Baleizão. Oeiras: Celta.

Ferraz, S. 1998. O movimento camponês no Bico do Papagaio. Sete Barracas em busca de um elo. Imperatriz: Ética Editora. 
Gallo, S. 2002. Reforma agrária em Montemor-o-Novo, o caso da UCP Maria Machado. Arquivos da Memória 12-13(7):170-182.

Hespanha, P. 1986. A distribuição de terras a pequenos agricultores. Uma política para "desproletarizar" a reforma agrária. Revista Crítica de Ciências Sociais (18-19-20):379-409.

Kautsky, K. 1986. A questão agrária. São Paulo: Ed. Nova Cultural.

Marx, K. 2008. O Capital: crítica da economia política: livro III. Rio de Janeiro: Civilização Brasileira.

Masseno, M. D. 1996. Apontamentos sobre a Constituição Agrária portuguesa, in Perspectivas constitucionais. Nos 20 anos da Constituição de 19976. Volume 1. Editado por J. Miranda. Coimbra: Coimbra Editora.

Medeiros, L. 2003. Reforma Agrária no Brasil. História e atualidade da luta pela terra. São Paulo: Editora Perseu Abramo.

Pereira, J. 2013. A luta política em torno da implementação do modelo de reforma agrária de mercado durante o governo Cardoso, in A questão agrária no Brasil - volume 8: debate sobre a situação e perspectivas da reforma agrária na década de 2000. Organizado por J. P. Stédile, pp. 19-68. São Paulo: Editora Expressão Popular.

Santos, B. S. 1984. A crise e a reconstituição do estado em Portugal (1974-84). Revista Crítica de Ciências Sociais (14):7-29.

Stédile, J. P. (Org.). 2005. A questão agrária no Brasil - volume 3: programas de reforma agrária: 19462003. São Paulo: Expressão Popular.

Stédile, J. P. 2013. Tendência do capital na agricultura, in A questão agrária no Brasil - volume 8: debate sobre a situação e perspectivas da reforma agrária na década de 2000. Organizado por J. P. Stédile, pp. 19-38. São Paulo: Expressão Popular. 
Stédile, J. P. 2020. Experiências Históricas de Reforma Agrária no Mundo - Volume 1. São Paulo: Editora Expressão Popular.

Vergolino, J. R., e G. M. Gomes. 2004. Metamorfoses da economia amazônica, in Amazônia, terra e civilização: uma trajetória de 60 anos. Organizado por A. D. Mendes. Belém: Banco da Amazônia. 